\title{
Dependence rate of smokers in undergraduate dental school
}

\author{
Dea Eka Afianita*, Sri Susilawati*, Dede Sutardjo* \\ *Department of Dental Public Health Faculty of Dentistry Universitas Padjadjaran
}

\begin{abstract}
Introduction: The habit of smoking, can cause dependence for smokers and also it can cause various diseases and health problems, both physical health and oral health. Smoking habits are also occured in the health students which they should show good example to the community to live a healthy lifestyle, including a role as well as to reduce their smoking habits, and also providing information to the effects of smoking. The purpose of this study was to determine the dependence rate of smoking in undergraduate Dental School Faculty of Dentistry, Padjadjaran University. Methods: This study was a descriptive type using the survey technique. Sampling was conducted with a snowball technique. The sample of 39 smokers comprising 24 men and 15 women. Respondents filled in questionnaires and the responses to questionnaires have different points to determine the level of smoking dependence. Results: The results shows that about $76.9 \%$ of the total sample included in the category of dependence rate of smoking are very low, $20.5 \%$ with a lower category, and $2.6 \%$ with the medium category. Conclusion: Smoker students in undergraduate Dental School has a very low level of dependence.
\end{abstract}

Keywords: Smoking dependence

\section{INTRODUCTION}

The percentage of smokers increased every year in developing countries. According to WHO data in 2008, the number of smokers in Indonesia is the third-largest in the world, which is 65 million smokers or $28 \%$ per resident (about 225 billion cigarettes per year). Based on Riskesdas data in $2010,34.7 \%$ of Indonesians or about 82 million people become an active smoker. ${ }^{1} \mathrm{~A}$ total of $13.5 \%$ of children and adolescents in Indonesia are active smokers. ${ }^{2}$

WHO, US CDC Atlanta and the Canadian Public Health Association developed Global Tobacco Surveillance System (GTSS) to get information about smoker's data. Global Tobacco Surveillance Sytem (GTSS) consists of the Global
Youth Tobacco Survey (GYTS) for schoolchildren (13-15 years), the Global School Personnel Survey (GSPS) and the Global Health Professional Survey (GHPS) for health profession. Indonesia has conducted GYTS and GHPS. The Global Health Professional Survey (GHPS) in Indonesia with thirdyear students at the Faculty of Medicine, Faculty of Dentistry, Nursing sciences and the Faculty of Pharmacy in response.

In 2006 Indonesia conducted GHPS with third-year medical students as respondents in the survey. Almost half (48.4\%) of medical students used to smoke. GHPS 2006 stated that the prevalence of medical student smoking is $9.3 \%$, males $(21.1 \%)$ and women (2.3\%). A quarter (33\%) Have felt like smoking less than 30 minutes after 
waking up in the morning, in females are $39.4 \%$, which is higher than men (31.9\%). These data shows a high level of smoking addiction.

Although medical students learn about the dangers of smoking, there are still students in the Faculty of Medicine and dentistry who smokes. These would be a problem for those in the future as health workers because they should show an excellent example to the patient to live a healthy way of life. 3 Dentists (and other health workers) should help and advise patients to quit smoking as to create a message to emphasize the importance of this problem. ${ }^{4}$ Aims of this research is to desribe the level of smoking dependence on the undergraduate Faculty of Medicine students in Dental University of Padjadjaran.

\section{METHODS}

The type of research used is descriptive method with a survey technique. This descriptive research is done towards a group of objects that usually aim to see an overview of the phenomenon occurring within a particular population. ${ }^{5}$

The population of this research is a bachelor degree in dentistry from the Faculty of Dentistry at Universitas Padjadjaran in February 2012, which are active smokers. The collection of the respondent's characteristics data and the level of reliance on the cigarette are done with pre-made questionnaire aids. This questionnaire is a raw questionnaire from the book Textbook of Preventive and Community Dentistry. 4 Questionnaire consists of six questions that have their points in each answer.

Sample is taken using snowball sampling technique, which a small number of samples continue to grow as if like a snowball. ${ }^{6}$ research is done by searching for several samples to be given a questionnaire, later on, researchers take five people as a first sample. Preliminary samples are set in small member groups. Each samples show other people who can act as a sample to the researcher so that the number of samples increases. This research is conducted at the Faculty of Dentistry in Padjadjaran University.

\section{RESULTS}

This study is conducted to identify the level of smoking dependence on undergraduate students of dentistry program in Faculty of Dentistry, Universitas Padjadjaran, which held at Padjadjaran University, Jatinangor. The total number of Students who smoked is 39 people, including male smoker (24 people) and female smokers as (15 people). Based on the results of the study, students of the undergraduate dentistry program Faculty of Dentistry, Universitas Padjadjaran, in February 2012, generally have a deficient level of smoking dependence, with a total number of 30 students and a percentage of $76.9 \%$.

The results of the research on the percentage of smoking dependence in undergraduate degree in Dentistry program of dentistry Padjadjaran University was divided into seven parts, including distribution of the sample based on smoking Period after Waking up, self-resistance to nonsmoking in forbidden places, hard-to-resist smoking period, number of smoked cigarettes, the frequency of smoking, the resistance to smoking during sick period, and the percentage of smoking dependence.

Table 1 shows a distribution of sample of smoking period after waking up. Respondents who smokes within less than 5 minutes after waking the bed got the higgest points, with a total of 3 points. Followed by respondents who smokes within 5-30 minutes after waking up got 2 points, the respondent who smokes within 31-60 minutes after waking up got 1 point, and the respondent

Tabel 1. Sample distribution based on smoking time after waking up

\begin{tabular}{lcl}
\hline Smoking period & Frequency & Percentage \\
\hline < 5 Minutes after waking up & 2 & 5.1 \\
5-30 Minutes after waking up & 4 & 10.3 \\
31-60 Minutes after waking up & 7 & 17.9 \\
>60 Minutes after waking up & 26 & 66.7 \\
\hline Total & 39 & $100 \%$ \\
\hline
\end{tabular}

Table 2. Sample distribution based on self-resistance to not smoke in forbidden places

\begin{tabular}{ccc}
\hline $\begin{array}{c}\text { Difficulty to not smoke in } \\
\text { forbidden places }\end{array}$ & Frequency & Percentage \\
\hline Yes & 5 & 12.8 \\
No & 34 & 87.2 \\
\hline Total & 39 & $100 \%$ \\
\hline
\end{tabular}


Tabel 3. Sample distribution based on period of time that is difficult to resists smoking

\begin{tabular}{clc}
\hline $\begin{array}{c}\text { Smoking period that is difficult } \\
\text { to stop }\end{array}$ & Frequency & Percentage \\
\hline Morning & 3 & 7.7 \\
Other period & 36 & 92.3 \\
\hline Total & 39 & $100 \%$ \\
\hline
\end{tabular}

Tabel 4. Sample distribution based on the total number of cigarettes smoked

\begin{tabular}{ccc}
\hline Total cigarettes smoked & Frequency & Percentage \\
\hline$<10$ cigarettes per day & 31 & 79.5 \\
11-20 cigarettes per day & 8 & 20.5 \\
21-30 cigaretes per day & 0 & 0 \\
$>30$ cigarettes per day & 0 & 0 \\
\hline Total & 39 & $100 \%$ \\
\hline
\end{tabular}

Tabel 5. Sample distribution based on frequency of smoking

\begin{tabular}{ccc}
\hline $\begin{array}{c}\text { More often smoke during the } \\
\text { morning }\end{array}$ & Frequency & Percentage \\
\hline Yes & 5 & 12.8 \\
No & 34 & 87.2 \\
\hline Total & 39 & $100 \%$ \\
\hline
\end{tabular}

who smokes within more than 60 minutes after waking up gets 0 points. Based on the results of the study, students who smoked in less than 5 minutes after waking is $5.1 \%$. Students who smoke within 5-30 minutes after waking up is $10.3 \%$. Students who smoke within 31-60 minutes after waking are $17.9 \%$. Students who smoke within more than 60 minutes after waking are $66.7 \%$ (Table 1 ).

A total of $87.2 \%$ of students were able to resist from smoking in forbidden places. Students who cannot resist from smoking in forbidden places are $12.8 \%$ (Table 2). A total of $7.7 \%$ students smoke during the morning. Students who smoke during another period is $92.3 \%$ (Table 3 ).

According to table 4 , the number of students who smoked less than ten cigarettes per day are $79.5 \%$. Students who smoked $11-20$ cigarettes are $20.5 \%$. No students are smoking more than 20 cigarettes per day.

According to table 5 ., as much as $12.8 \%$ of student more often smokes after waking up. Students smoke at other period of times are $87.2 \%$. According to Table 6 ., as many as $25.6 \%$ of students remain smoked in times of illness. Students who
Tabel 6. Sample distribution based on self-needs to not smoke during sick period

\begin{tabular}{cccc}
\hline Smokes during sick period & Frequency & Percentage \\
\hline & Yes & 10 & 25.6 \\
& No & 29 & 74.4 \\
\hline Total & 39 & $100 \%$ \\
\hline
\end{tabular}

Tabel 7. Percentage of self needs of smoking

\begin{tabular}{ccc}
\hline Category & Frequency & Percentage \\
\hline Sangat rendah & 30 & 76.9 \\
Rendah & 8 & 20.5 \\
Sedang & 1 & 2.6 \\
Tinggi & 0 & 0 \\
Sangat Tinggi & 0 & 0 \\
\hline Total & 39 & $100 \%$ \\
\hline
\end{tabular}

do not smoke at the time of illness as much as 74.4\% (Table 6).

Based on the research, there are no undergraduate students in the Faculty of Dentistry, Universitas Padjadjaran, which has a high level of dependence. Most respondents, of which $76.9 \%$ have a very low dependency rate, followed by $20.5 \%$ who have a low dependency rate, and the remainder as much as $2.6 \%$ have a moderate level of dependency (Table 7).

\section{DISCUSSION}

The results showed from a total of 431 students of the undergraduate dental program of Dentistry Padjadjaran University in February 2012, 39 of whom are smokers, with the number of male smokers are 24 people, and Women is 15 people. From these 39 people, 30 of them have a very low dependency rate.

This research is an advanced study of the research that conducts GHPS (Global Health Professional Survey) in Indonesia on third-degree medical students as respondents. The outcome of the smoking prevalence of medical students is $9.3 \%$, and a third $(33 \%)$ Have a high degree of dependence.

The results of the research of GHPS 2006 were not comparable to the research that the author did. In research on undergraduate program students of Dentistry Faculty of Dentistry Universitas Padjadjaran, there are no students 
who have high levels of smoking dependence, mostly or about $76.9 \%$ have Very low dependence.

In research GHPS 2006, the level of dependency smoking is determined by the question of whether the respondent has felt wanting to smoke less than 30 minutes after waking up in the morning. The authors assessed the level of smoking dependence from seven questions. The question is constitute with modification from Textbook of Preventive and Community Dentistry. ${ }^{4}$ Any answers in questions have their points that can then be Determine whether the respondent has a very low, low, moderate, high, or even high dependency rate.

The first question is a preliminary question that asks whether the respondent has a habit of smoking or not. Of the multiple shared questionnaires, as many as 39 people or $0.09 \%$ replied "yes". Respondents who answered "yes" is an active smoker, active smokers are people who smoke and immediately smoke cigarettes and can cause harm to the health of the self and the environment. ${ }^{7}$

Second question is similar to the question being done on GHPS 2006, which is to inquire how long the gap period after waking up in the morning until the respondent has felt like smoking. The result is $5.1 \%$ of smoking respondents in less than 5 minutes after waking up. While the students are smoking within 5-30 minutes after waking up as much as $10.3 \%$. Students who smoke within 31 60 minutes after waking up as much as $17.9 \%$. Students who smoke in time more than 60 minutes after waking up as much as $66.7 \%$ (Table 1.).

Research conducted by Muscat from the Pennsylvania State College of Medicine in the United States showed a habit of smoking in the morning, especially after waking up has a larger risk of developing cancer. The study involved 9,400 individuals by conducting questionnaires to assess the customs of the Merokoknya. Patients newly diagnosed with cancer are also included in the research and matched with the control data, as well as all participants here are smokers or former smokers.

The first analysis found is that people who consume the first cigarette within 30 minutes after waking up have a risk of 1.79 times more likely to develop lung cancer and 1.59 times more risk of developing head and neck cancer than
Smokers who can hold themselves for 1 hour or so. People who smoke the first time at 31-60 minutes after waking up have a risk of 1.31 times higher developing lung cancer as well as 1.42 fold higher risk of cancer of the head and neck.

A third question about the resilience of not smoking in public places or in place of smoking ban. The results showed as many as $12.8 \%$ of students of the undergraduate dentistry Faculty of Dentistry Universitas Padjadjaran was unable to refrain from smoking in public places. The answering respondent could not refrain from smoking in place of smoking ban got 1 point, and the respondent who claimed to refrain from smoking in the place got 0 points.

The research on the resilience of nonsmoking in public places has been done by YLKI (Indonesia Institute of Consumers Foundation) in 2011 in involving 420 respondents. YLKI surveys the understanding and obedience of the Jakarta citizen to the regulation of the Governor No. 88 year 2010 of KDM (smoking area prohibited). The survey was conducted against 210 places, comprising 70 hotels, 70 restaurants and 70 private workplaces in Jakarta. As a result the survey team encountered more than $57 \%$ of smokers at the hotel, $47 \%$ of smokers in the restaurant, and $70 \%$ of smokers in the private workplace violated KDM.

Various reasons so pretext respondents when interviewed the survey team. Some keep smoking because it feels there is no supervision. Some others profess to see no smoking sign, some even claim that there is no strict sanction if it is forbidden.

The fourth question on this questionnaire aims to know when the most difficult time left to smoke, whether in the morning or at any other time. Only a small part of the respondent is difficult to leave the smoking activity in the morning, which is $7.7 \%$. Respondents who answered it was harder to leave the smoking activity in the morning than the other time got 1 point. Taylor in 2006 revealed that the frequency of smoking affects the levels of nicotine in the body. When the nicotine level in the blood drops, smokers will continue to smoke until their needs are satisfied. In the morning, after waking up, usually the level of nicotine in the blood has decreased. Therefore, addicted smoker wants to smoke in the morning.

The sixth question asks about whether the 
respondent is more smoked after waking up than any other time. Only $12.8 \%$ of the respondents claimed to smoke after waking up, this of course indicated that it had been subjected to dependency. Respondents who answered more smoking after waking up got 1 point and who answered another time got 0 points.

The seventh question or the last question on this questionnaire aims to know whether at the time of sekit or bed rest the respondent quit smoking or keep smoking. It turns out that about $25.6 \%$ of respondents admitted they remained smoking despite being sick. It indicates that the respondent has had a smoking dependency because they cannot resist smoking even if it is in an unhealthy state.

The number of points gained from the questions in the questionnaire is then aggregated. If the number is 0 to 2 , then the rate of dependency smoking respondent belongs to very low category. When the number is 3 to 4 , then the level of smoking respondent is included in the low category, when the number is 5 , the level of The smoking dependency of the respondent belongs to the medium category. If the amount is 6 to 8 , then the level of smoking respondent dependence belongs to the high category, when the number is 9 to 10 , then the level of smoking respondent dependency including In a very high category. Based on the results of the study, most students of the undergraduate Dentistry College of Dentistry have a very low smoking dependence rate. No one is experiencing high levels of smoking dependence or a very high category.

\section{CONCLUSION}

Smoker students in undergraduate Dental School has a very low level of dependence.

\section{REFERENCES}

1. Balitbangkes. Riset Kesehatan Dasar. Available from: http://www.riskesdas .litbang.depkes. go.id.download/TabelRiskesdas2010.pdf [Cited 5 Dec 2011). 2010.

2. WHO. Reducing Death from Tobacco. World Health Statistic 2008. 2008.

3. Geller AC, Zapka J, Brooks KR, Dube C, Powers CA, Rigotti N et al. Tobacco Control Competencies for US Medical Students. Am J Public Health. 2005 Jun;95(6):950-5.

4. Hiremath S. Tobacco use, Effects on Health and Management. In Textbook of Preventive and Community Dentistry. New Delhi: Elsevier India Private Limited: 2007. p. 520-22.

5. Notoatmojo. Promosi Kesehatan: Teori dan Aplikasi. Jakarta: Rhineka Cipta. 2010.

6. Riduwan. Belajar mudah penelitian untuk guru, karyawan dan peneliti pemula. Bandung: Alfabeta. 2005.

7. Bustan NM. Epidemiologi penyakit tidak menular. Jakarta: Rineka Cipta. 1997.

8. Mangoenprasodo, Hidayati. Hidup sehat tanpa rokok. Yogyakarta: Pradipta Publishing. 2005. 